\title{
Communication
}

\section{Real Time Observation of Lithium Insertion into Pre-Cycled Conversion-Type Materials}

\author{
Sooyeon Hwang * and Dong Su
}

check for

updates

Citation: Hwang, S.; Su, D. Real Time Observation of Lithium Insertion into Pre-Cycled Conversion-Type Materials. Nanomaterials 2021, 11, 728. https:// doi.org/10.3390/nano11030728

Academic Editor: Carlos Miguel Costa

Received: 9 February 2021

Accepted: 11 March 2021

Published: 14 March 2021

Publisher's Note: MDPI stays neutral with regard to jurisdictional claims in published maps and institutional affiliations.

Copyright: (c) 2021 by the authors. Licensee MDPI, Basel, Switzerland. This article is an open access article distributed under the terms and conditions of the Creative Commons Attribution (CC BY) license (https:/ / creativecommons.org/licenses/by/ $4.0 /)$.
Center for Functional Nanomaterials, Brookhaven National Laboratory, Upton, NY 11973, USA; dongsu@iphy.ac.cn

* Correspondence: soohwang@bnl.gov

Abstract: Conversion-type electrode materials for lithium-ion batteries experience significant structural changes during the first discharge-charge cycle, where a single particle is taken apart into a number of nanoparticles. This structural evolution may affect the following lithium insertion reactions; however, how lithiation occurs in pre-cycled electrode materials is elusive. In this work, in situ transmission electron microscopy was employed to see the lithium-induced structural and chemical evolutions in pre-cycled nickel oxide as a model system. The introduction of lithium ions induced the evolution of metallic nickel, with volume expansion as a result of a conversion reaction. After pre-cycling, the phase evolutions occurred in two separate areas almost at the same time. This is different from the first lithiation, where the phase change takes place successively, with a boundary dividing the reacted and unreacted areas. Structural changes were restricted at the areas having large amount of fluorine, implying the residuals from the decomposition of electrolytes may have hindered the electrochemical reactions. This work provides insights into phase and chemical evolutions in pre-cycled conversion-type materials, which govern electrochemical properties during operation.

Keywords: lithium-ion batteries; conversion; in situ TEM; lithiation

\section{Introduction}

Conversion-type electrode materials (MX, where $\mathrm{M}$ is generally a transition metal ion and $\mathrm{X}$ is $\mathrm{O}, \mathrm{S}, \mathrm{F}$, etc.) have been extensively explored, as they can deliver much higher capacities than intercalation-type materials [1-6]. When lithium ions are introduced, $\mathrm{MX}$ is converted into $\mathrm{M}$ and $\mathrm{Li}-\mathrm{X}$ via the conversion reaction. From a structural point of view, MX is decomposed into a composite of $\mathrm{M}$ nanocrystals and Li-X matrix with the introduction of lithium ions, then the composite is rearranged into MX nanocrystals when the lithium ions are removed. Structural evolutions during the first discharge-charge cycle may change the local environments around the electrode material (strain, defects, or other microscopic factors) through volume expansion [7] and fragmentation of the bulk active material; therefore, subsequent electrochemical reactions and corresponding phase evolutions may occur in different ways than those at the initial reaction. Despite the fact that the dynamic phase evolutions at the first lithiation have been thoroughly investigated by in situ transmission electron microscopy (TEM), [8-13] the knowledge achieved from the first lithium insertion may not be applicable to understanding the structural changes in the second and following cycles. Ex situ TEM works have provided significant insights into discovering the conversion mechanisms for multiple cycles [14-17] but it is hard to understand reaction dynamics via postmortem studies. It is of importance to observe how the phase evolutions after the first cycle take place in real time since they determine the electrochemical performances during operation. However, it is still elusive how lithiation occurs in pre-cycled conversion materials.

In this work, in situ TEM was exploited to track the lithiation reaction in pre-cycled $\mathrm{NiO}$ as TEM is a powerful tool for investigating the physical and chemical properties of nanomaterials, and is also capable of constructing an open-cell configuration [8-13]. $\mathrm{NiO}$ 
was selected as a model system since its single redox $\left(\mathrm{Ni}^{2+} \leftrightarrow \mathrm{Ni}^{0}\right)$ and corresponding phase change $(\mathrm{NiO} \leftrightarrow \mathrm{Ni})$ are straightforwardly interpreted. The reconstruction of nano $\mathrm{NiO}$ in pre-cycled $\mathrm{NiO}$ resulted in different reaction behaviors during the conversion reaction. The local chemical composition also affected the occurrence of phase evolutions. This work exhibits the second lithiation reaction in conversion-type materials, which is different from the initial one and more relevant to actual battery operation.

\section{Materials and Methods}

The electrode was prepared as mixed slurries with $80 \mathrm{wt} . \%$ of the active NiO, $10 \mathrm{wt} . \%$ of carbon black, and $10 \mathrm{wt} . \%$ of polyvinylidene fluoride (PVDF) binder in an N-methyl pyrrolidone (NMP) solvent for an electrochemical test. The synthesis of the NiO sample was delineated in a previous report [9]. The well-mixed slurry was coated onto a Cu metal foil, which acted as a current collector. Coin cells of 2032-type were assembled with an as-prepared electrode, a Celgard separator, Li metal, and an electrolyte of $1 \mathrm{M} \mathrm{LiPF}_{6}$ in ethylene carbonate/dimethyl carbonate (DMC) (1:1 in weight) inside an Ar-filled glove box. A lacey carbon film on a copper TEM grid with dispersed $\mathrm{NiO}$ was also inserted into a coin cell for the forthcoming in situ TEM experiment. The coin cells were tested within a voltage range of $0.1-3 \mathrm{~V}$ at a rate of $\mathrm{C} / 10$ using galvanostatic conditions on an Arbin BT2000 battery test station (Arbin Instruments, College Station, TX, USA). After the electrochemical tests, the coin cells were disassembled inside the Ar-filled glove box and the TEM grid was thoroughly washed with DMC to remove residual salts. In situ TEM observations and analytical TEM analysis were performed with a JEM-2100F (JEOL, Tokyo, Japan) at an accelerating voltage of $200 \mathrm{kV}$. A scanning tunneling microscopy (STM)-TEM holder (Nanofactory Instruments, Göteborg, Sweden) was used to construct an open cell, where $\mathrm{Li} / \mathrm{Li}_{2} \mathrm{O}$ on a piezo-driven $\mathrm{W}$ tip served as an anode/solid electrolyte, the lacey carbon film on the $\mathrm{Cu}$ TEM grid worked as the conducting agent and current collector, and cycled $\mathrm{NiO}$ samples were the working electrodes. During the in situ lithiation, a constant negative bias was applied to the samples to promote the movement of the $\mathrm{Li}$.

\section{Results and Discussion}

Figure 1a presents a high-resolution transmission electron microscopy (HRTEM) image and fast Fourier transformation (FFT) result of pristine $\mathrm{NiO}$. It is clear that the $\mathrm{NiO}$ was well-crystallized and obtained a long-range order before the electrochemical tests. After a discharge-charge cycle (Figure $1 \mathrm{~b}$ ), the microstructure of the $\mathrm{NiO}$ was completely changed, as shown in Figure 1c. During a discharge (lithiation), a conversion reaction occurred in the $\mathrm{NiO}\left(\mathrm{NiO}+\mathrm{Li}^{+} \rightarrow \mathrm{Ni}+\mathrm{Li}_{2} \mathrm{O}\right)$, where $\mathrm{Ni}$ nanoparticles were formed with a matrix of $\mathrm{Li}_{2} \mathrm{O}[9,18]$. Figure $1 \mathrm{c}$ suggests a charge (delithiation) took place in a way that each $\mathrm{Ni}$ nanoparticle became oxidized. The ring pattern of the FFT result (inset of Figure 1c) also indicates the active material consisted of a number of nanoparticles. The electron energy loss spectroscopy (EELS) elemental maps of $\mathrm{Ni}$ and $\mathrm{O}$ (Figure 1d) present the coexistence of $\mathrm{Ni}$ and $\mathrm{O}$. The fluorine elemental map shows a trace amount of $\mathrm{F}$ was evenly distributed, which can be contributed to the uniform formation of a solid electrolyte interphase (SEI). The EELS spectrum of NiO after one cycle in Figure 1e is comparable with the one from the $\mathrm{NiO}$ reference, implying that nanocrystalline $\mathrm{NiO}$ was obtained after a discharge-charge cycle.

The lithium insertion reaction in the pre-cycled $\mathrm{NiO}$ was observed in real time. An open cell was constructed inside of the TEM, as shown in previous reports $[9,11,19]$. Figure 2a presents a time-series of high-angle annular dark-field scanning TEM (HAADFSTEM) images during lithiation. A video showing the lithiation reaction is also provided as Video S1 in the Supplementary Materials. As lithium ions were introduced, an expansion of the active material was noticed. The changes in the widths of the pre-cycled $\mathrm{NiO}$ in different regions, labeled " $A$ " and " $B$ " (Figure 2a), were tracked for the duration of lithiation (Figure 2b), showing a continuous increase in both A and B. It is noteworthy that volume expansions were noticed in two separate areas simultaneously, indicating 
that the conversion reaction did not occur successively. Previous works reported the initial conversion reactions are a two-phase reaction, where a phase boundary between the reacted and unreacted areas is apparent and the phase boundary moves as lithium ions keep diffusing into the material $[10,20-23]$. Here, the conversion reaction started in the regions away from each other concurrently (Figure 2a,b), which may result in an S-like discharge profile during the second and following cycles, while the voltage profile shows a plateau during the initial discharge $[2,24,25]$. The width of the pre-cycled $\mathrm{NiO}$ in region $\mathrm{A}$ increased by $41.24 \%$, while that in region B increased by $20.11 \%$ during observation. Considering that the $\mathrm{NiO}$ sample had the morphology of nanosheet $[9,23]$, volume expansion along the z-direction was expected to be negligible. Thus, $99.26 \%$ and $44.26 \%$ of volume expansion were expected in regions A and B, respectively. Comparing the estimated volume expansion of the $\mathrm{NiO}$ with reference [7] suggests that most of the active materials underwent the conversion reaction around region $\mathrm{A}$, while only a portion of the materials reacted with the lithium around region $B$. The degree of conversion reaction may differ depending on the distance from the lithium source. As lithiation proceeded, particulates in the pre-cycled $\mathrm{NiO}$ became larger (Figure $2 \mathrm{~b}$ ). According to the Z-contrast of the HAADF-STEM, we can conjecture that the brighter particulates in the HAADF-STEM image acquired at $211 \mathrm{~s}$ in Figure 2a were composed of an element with a high atomic number (Z), in this case, Ni. The bigger size of Ni particles (211 s) compared to the $\mathrm{NiO}(0 \mathrm{~s})$ suggests that the metallic $\mathrm{Ni}$ might have been agglomerated during the conversion reaction since the unit cell of the $\mathrm{Ni}$ is smaller than that of the $\mathrm{NiO}$. Figure $2 \mathrm{c}, \mathrm{d}$ shows selected area electron diffraction (SAED) patterns acquired before and after in situ lithiation, demonstrating that the $\mathrm{NiO}$ was converted into $\mathrm{Ni}$ and $\mathrm{Li}_{2} \mathrm{O}$ as a result of the conversion reaction.
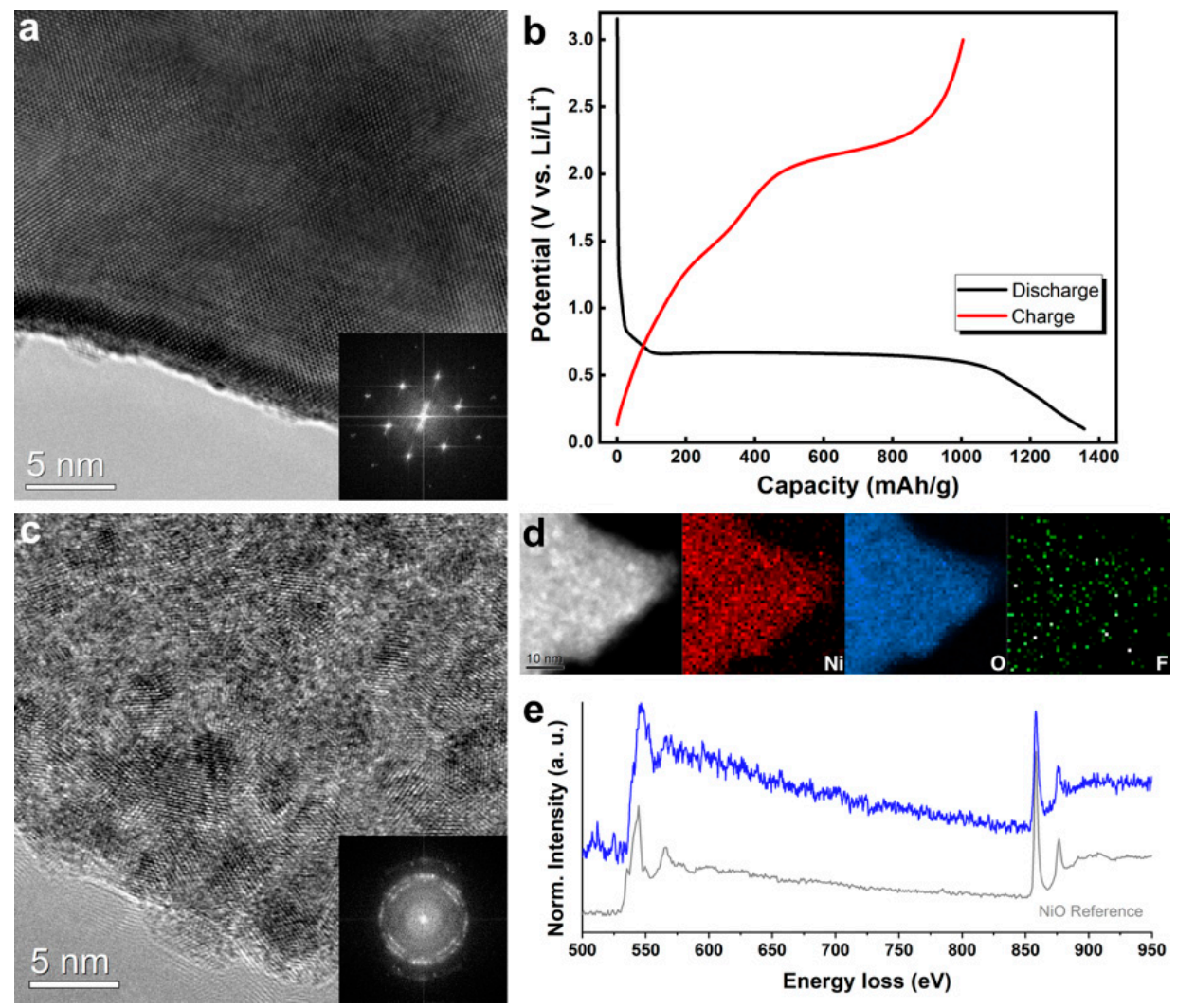

Figure 1. (a) A high-resolution TEM (HRTEM) image of pristine NiO. (b)The discharge-charge voltage profiles for the first cycles acquired from a coin cell. (c) An HRTEM image and (d) a high-angle annular dark-field scanning TEM (HAADF-STEM) image and the corresponding STEMelectron energy loss spectroscopy (EELS) Ni, O, and F elemental maps obtained from pre-cycled NiO. (e) EELS acquired from the $\mathrm{NiO}$ after the first cycle with that of the $\mathrm{NiO}$ reference. 

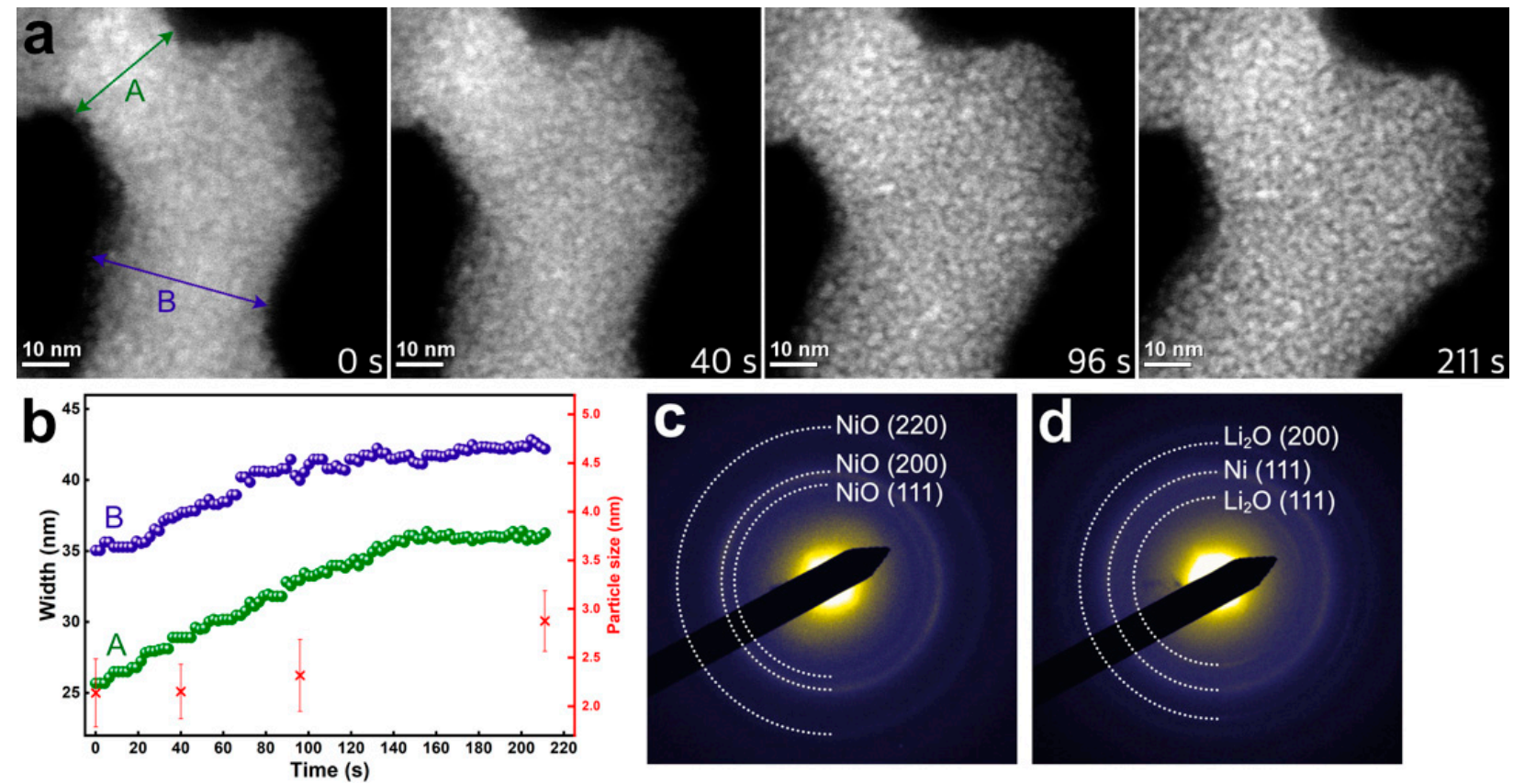

Figure 2. (a) Time-series HAADF-STEM images of pre-cycled $\mathrm{NiO}$ during lithiation. (b) The changes in the width of A and $\mathrm{B}$ in (a) and size of inside particles with lithiation. Selected area electron diffraction (SAED) patterns of (c) before and (d) after in situ lithium insertion.

Chemical inhomogeneity was observed in the pre-cycled NiO samples. Figure $3 \mathrm{a}$ shows an EELS spectrum acquired from the $\mathrm{NiO}$ after an electrochemical cycle, presenting an additional edge around $685 \mathrm{eV}$ compared to the spectrum in Figure 1e. It was determined to be the fluorine K-edge, which can originate from the residuals of decomposed electrolytes during prior electrochemical tests in a coin cell. The SAED acquired in the area containing $F$ (Figure $3 \mathrm{~b}$ ) indicates that the $\mathrm{NiO}$ was nanocrystalline, while the F-containing species were amorphous. After in situ lithiation for $466 \mathrm{~s}$ (Supplementary Materials, Video S2), a ring pattern from the $\mathrm{NiO}$ was well-kept, while ring patterns from the lithium oxide evolved (Figure 3c). This explains that the conversion reaction did not occur, though lithium ions were transported into the $\mathrm{NiO}$. Diffused $\mathrm{Li}$ ions were transformed into $\mathrm{Li}_{2} \mathrm{O}$ rather than participating in the conversion reaction in the area with $\mathrm{F}$, implying that the products from the decomposition of electrolytes may have limited the electrochemical reactions in the active materials. Figure 3d,e exhibits HAADF-STEM images acquired before and after in situ lithiation, where the conversion reaction did not occur, demonstrating that the formation of $\mathrm{Li}_{2} \mathrm{O}$ took place on the surface of the pre-cycled $\mathrm{NiO}$, which is distinct from the formation of the $\mathrm{Li}_{2} \mathrm{O}$ through the conversion reaction shown in Figure 2. $\mathrm{As}^{\mathrm{Li}_{2} \mathrm{O} \text { was }}$ the electrical insulator, the development of $\mathrm{Li}_{2} \mathrm{O}$ on the surface of active material can be another obstacle for electrochemical reactions.

Figure 4 summarizes findings of this work. As a result of a full discharge-charge electrochemical cycle, the whole $\mathrm{NiO}$ was disintegrated into a number of $\mathrm{NiO}$ nanoparticles. Depending on the amount of $\mathrm{F}$ around the $\mathrm{NiO}$ particles, different reaction behaviors were observed. Areas with the trace amount of $\mathrm{F}$ around $\mathrm{NiO}$ nanoparticles (green lines around $\mathrm{NiO}$ in Figure 4) were electrochemically active where a thin SEI layer was desirably formed. Thus, we can see the conversion reaction occurred when the lithium ions were introduced. Meanwhile, the pre-cycled $\mathrm{NiO}$ covered by thick F-containing species could not take part in the phase evolutions with Li ions, suggesting that products from the electrolyte decomposition may hinder the electrochemical reactions. 

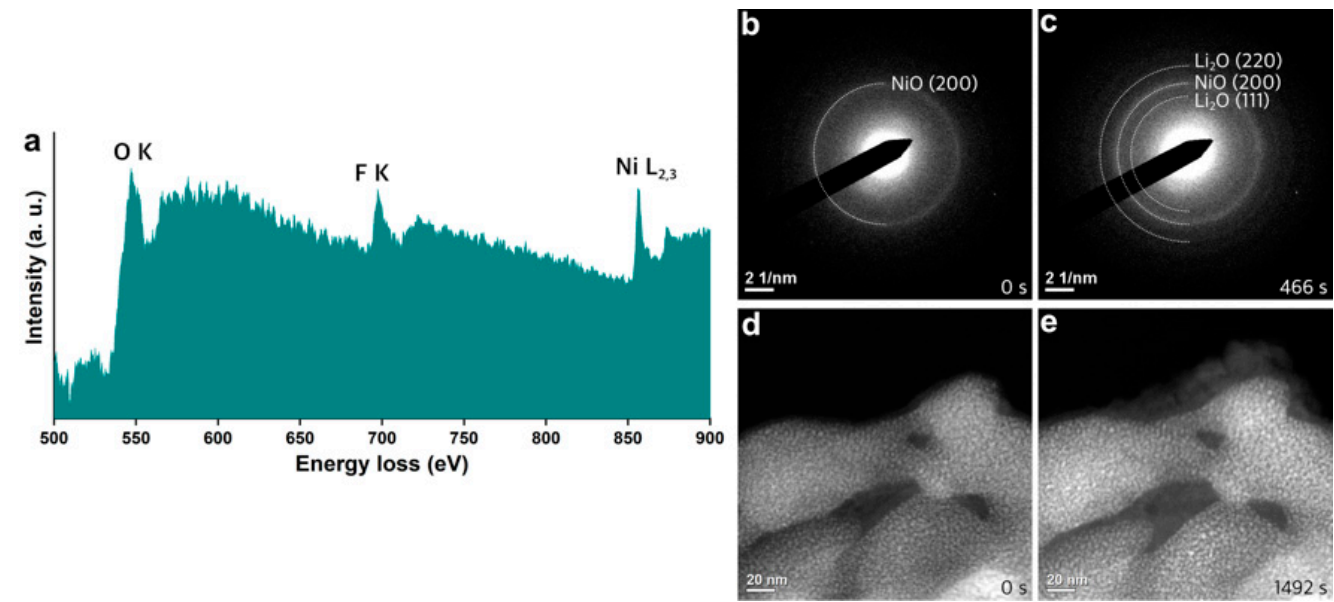

Figure 3. (a) EELS acquired from a part of pre-cycled NiO. SAED patterns and HAADF-STEM images obtained $(\mathbf{b}, \mathbf{d})$ before and $(\mathbf{c}, \mathbf{e})$ after in situ lithiation. In situ experiments were performed separately for the acquisition of SAED and HAADF-STEM.
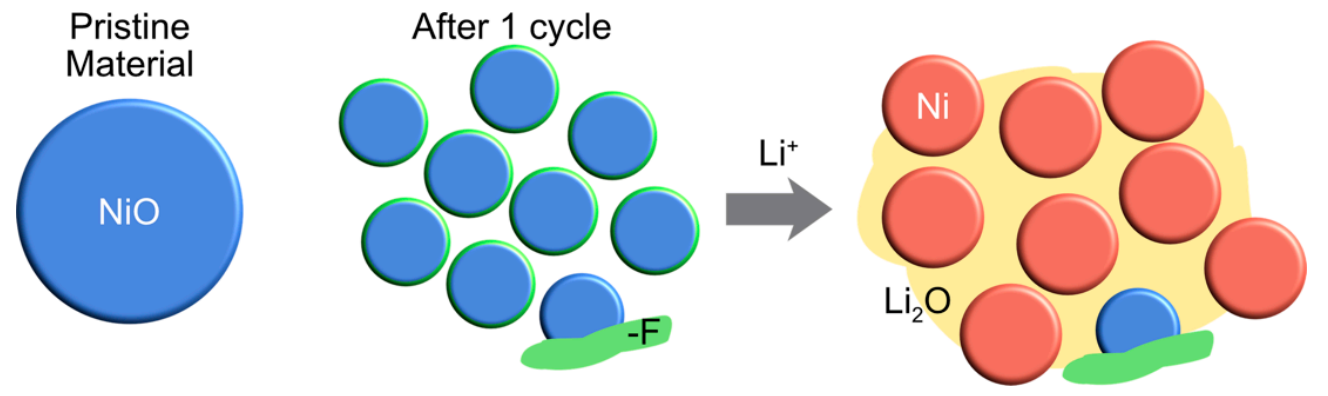

Figure 4. A schematic showing the structural evolution during the second lithiation.

\section{Conclusions}

In this work, in situ electron microscopy was exploited to demonstrate the phase evolutions of pre-cycled conversion-type metal oxide materials during lithiation. The initial discharge-charge process of active materials led to converting the bulk material into a bunch of nanocrystals. Structural change may have produced the new reaction routes, reflecting that the conversion-induced volume expansion was observed simultaneously in two separate areas. S-like voltage profiles for the second and following discharge processes might have been associated with concurrent structural evolutions. Conversion reactions were not observed in the region containing substantial amount of fluorine, implying that the decomposition of electrolytes should be desirably controlled to not limit the usage of active materials. This work visualizes the lithiation reaction in pre-cycled conversion-type materials, and is related to electrochemical performances for practical operation.

Supplementary Materials: The following are available online at https: / /www.mdpi.com/2079-4 991/11/3/728/s1: Video S1: HAADF-STEM real time movie during the lithiation reaction in the pre-cycled NiO. Accelerated 15 times. Video S2: SAED was recorded during lithiation, where a conversion reaction did not occur. Accelerated 50 times.

Author Contributions: Conceptualization, S.H. and D.S.; methodology, S.H.; formal analysis, S.H.; investigation, S.H.; writing—original draft preparation, S.H.; writing—review and editing, D.S. All authors have read and agreed to the published version of the manuscript.

Funding: This research received no external funding.

Data Availability Statement: The data presented in this study are available on request from the corresponding author. 
Acknowledgments: This work is supported by the Center for Functional Nanomaterials, which is a US DOE Office of Science Facility, at Brookhaven National Laboratory under Contract No. DESC0012704. We appreciate Feng Lin and Ryan M. Richards for providing the NiO samples.

Conflicts of Interest: The authors declare no conflict of interest.

\section{References}

1. Poizot, P.; Laruelle, S.; Grugeon, S.; Dupont, L.; Tarascon, J.-M. Nano-Sized Transition-Metal Oxides as Negative-Electrode Materials for Lithium-Ion Batteries. Nature 2000, 407, 496-499. [CrossRef] [PubMed]

2. Cabana, J.; Monconduit, L.; Larcher, D.; Palacín, M.R. Beyond Intercalation-Based Li-Ion Batteries: The State of the Art and Challenges of Electrode Materials Reacting Through Conversion Reactions. Adv. Mater. 2010, 22, 170-192. [CrossRef] [PubMed]

3. Taberna, P.L.; Mitra, S.; Poizot, P.; Simon, P.; Tarascon, J.-M. High Rate Capabilities Fe3O4-Based Cu Nano-Architectured Electrodes for Lithium-Ion Battery Applications. Nat. Mater. 2006, 5, 567-573. [CrossRef]

4. Chae, B.-M.; Oh, E.-S.; Lee, Y.-K. Conversion Mechanisms of Cobalt Oxide Anode for Li-Ion Battery: In situ X-Ray Absorption Fine Structure Studies. J. Power Sources 2015, 274, 748-754. [CrossRef]

5. Wang, H.; Cui, L.-F.; Yang, Y.; Sanchez Casalongue, H.; Robinson, J.T.; Liang, Y.; Cui, Y.; Dai, H. Mn3O4-Graphene Hybrid as a High-Capacity Anode Material for Lithium Ion Batteries. J. Am. Chem. Soc. 2010, 132, 13978-13980. [CrossRef]

6. Xiao, A.W.; Lee, H.J.; Capone, I.; Robertson, A.; Wi, T.-U.; Fawdon, J.; Wheeler, S.; Lee, H.-W.; Grobert, N.; Pasta, M. Understanding the Conversion Mechanism and Performance of Monodisperse Fef2 Nanocrystal Cathodes. Nat. Mater. 2020, 19, 644-654. [CrossRef]

7. Ponrouch, A.; Taberna, P.-L.; Simon, P.; Palacín, M.R. On the Origin of the Extra Capacity at Low Potential in Materials for Li Batteries Reacting Through Conversion Reaction. Electrochim. Acta 2012, 61, 13-18. [CrossRef]

8. Wang, F.; Robert, R.; Chernova, N.A.; Pereira, N.; Omenya, F.; Badway, F.; Hua, X.; Ruotolo, M.; Zhang, R.; Wu, L.; et al. Conversion Reaction Mechanisms in Lithium Ion Batteries: Study of the Binary Metal Fluoride Electrodes. J. Am. Chem. Soc. 2011, 133, 18828-18836. [CrossRef]

9. He, K.; Xin, H.L.; Zhao, K.; Yu, X.; Nordlund, D.; Weng, T.-C.; Li, J.; Jiang, Y.; Cadigan, C.A.; Richards, R.M.; et al. Transitions from Near-Surface to Interior Redox upon Lithiation in Conversion Electrode Materials. Nano Lett. 2015, 15, 1437-1444. [CrossRef] [PubMed]

10. He, K.; Zhang, S.; Li, J.; Yu, X.; Meng, Q.; Zhu, Y.; Hu, E.; Sun, K.; Yun, H.; Yang, X.-Q.; et al. Visualizing Non-Equilibrium Lithiation of Spinel Oxide Via in Situ Transmission Electron Microscopy. Nat. Commun. 2016, 7, 11441. [CrossRef]

11. Su, Q.; Xie, D.; Zhang, J.; Du, G.; Xu, B. In Situ Transmission Electron Microscopy Observation of the Conversion Mechanism of Fe2O3/Graphene Anode during Lithiation-Delithiation Processes. ACS Nano 2013, 7, 9115-9121. [CrossRef] [PubMed]

12. Li, J.; Meng, Q.; Zhang, Y.; Peng, L.; Yu, G.; Marschilok, A.C.; Wu, L.; Su, D.; Takeuchi, K.J.; Takeuchi, E.S.; et al. Size-Dependent Kinetics During Non-Equilibrium Lithiation of Nano-Sized Zinc Ferrite. Nat. Commun. 2019, 10, 93. [CrossRef]

13. Hwang, S.; Meng, Q.; Chen, P.-F.; Kisslinger, K.; Cen, J.; Orlov, A.; Zhu, Y.; Stach, E.A.; Chu, Y.-H.; Su, D. Strain Coupling of Conversion-type Fe3O4 Thin Films for Lithium Ion Batteries. Angew. Chem. Int. Ed. 2017, 56, 7813-7816. [CrossRef]

14. Dupont, L.; Grugeon, S.; Laruelle, S.; Tarascon, J.-M. Structure, Texture and Reactivity Versus Lithium of Chromium-Based Oxides Films as Revealed by TEM Investigations. J. Power Sources 2007, 164, 839-848. [CrossRef]

15. Débart, A.; Dupont, L.; Poizot, P.; Leriche, J.-B.; Tarascon, J.-M. A Transmission Electron Microscopy Study of the Reactivity Mechanism of Tailor-Made CuO Particles toward Lithium. J. Electrochem. Soc. 2001, 148, A1266-A1274. [CrossRef]

16. Grugeon, S.; Laruelle, S.; Dupont, L.; Tarascon, J.-M. An Update on the Reactivity of Nanoparticles Co-based Compounds towards Li. Solid State Sci. 2003, 5, 895-904. [CrossRef]

17. Débart, A.; Dupont, L.; Patrice, R.; Tarascon, J.-M. Reactivity of Transition Metal (Co, Ni, Cu) Sulphides versus Lithium: The Intriguing Case of the Copper Sulphide. Solid State Sci. 2006, 8, 640-651. [CrossRef]

18. Zhu, Y.; Li, C.; Wang, Q.; Wang, J.; Chen, L.; Gu, M. Fast Lithiation of NiO Investigated by in Situ Transmission Electron Microscopy. Appl. Phys. Lett. 2019, 115, 143902. [CrossRef]

19. McDowell, M.T.; Lee, S.W.; Harris, J.T.; Korgel, B.A.; Wang, C.; Nix, W.D.; Cui, Y. In Situ TEM of Two-Phase Lithiation of Amorphous Silicon Nanospheres. Nano Lett. 2013, 13, 758-764. [CrossRef]

20. Boebinger, M.G.; Yeh, D.; Xu, M.; Miles, B.C.; Wang, B.; Papakyriakou, M.; Lewis, J.A.; Kondekar, N.P.; Cortes, F.J.Q.; Hwang, S.; et al. Avoiding Fracture in a Conversion Battery Material through Reaction with Larger Ions. Joule 2018, 2, 1783-1799. [CrossRef]

21. Hwang, S.; Yao, Z.; Zhang, L.; Fu, M.; He, K.; Mai, L.; Wolverton, C.; Su, D. Multistep Lithiation of Tin Sulfide: An Investigation Using in SituElectron Microscopy. ACS Nano 2018, 12, 3638-3645. [CrossRef] [PubMed]

22. Li, J.; He, K.; Meng, Q.; Li, X.; Zhu, Y.; Hwang, S.; Sun, K.; Gan, H.; Zhu, Y.; Mo, Y.; et al. Kinetic Phase Evolution of Spinel Cobalt Oxide during Lithiation. ACS Nano 2016, 10, 9577-9585. [CrossRef] [PubMed]

23. He, K.; Lin, F.; Zhu, Y.; Yu, X.; Li, J.; Lin, R.; Nordlund, D.; Weng, T.-C.; Richards, R.M.; Yang, X.-Q.; et al. Sodiation Kinetics of Metal Oxide Conversion Electrodes: A Comparative Study with Lithiation. Nano Lett. 2015, 15, 5755-5763. [CrossRef] [PubMed]

24. Varghese, B.; Reddy, M.V.; Yanwu, Z.; Lit, C.S.; Hoong, T.C.; Subba Rao, G.V.; Chowdari, B.V.R.; Wee, A.T.S.; Lim, C.T.; Sow, C.-H. Fabrication of NiO Nanowall Electrodes for High Performance Lithium Ion Battery. Chem. Mater. 2008, 20, 3360-3367. [CrossRef]

25. Huang, X.H.; Tu, J.P.; Zhang, B.; Zhang, C.Q.; Li, Y.; Yuan, Y.F.; Wu, H.M. Electrochemical Properties of NiO-Ni Nanocomposite as Anode Material for Lithium Ion Batteries. J. Power Sources 2006, 161, 541-544. [CrossRef] 